\title{
Material study of a liturgical cope from the $16^{\text {th }}$ century
}

Ferreira, T. , Moreiras, H. , Manhita, A.. , Frade, C. ${ }^{* *}$, Lopes, E. ${ }^{* *}$, Tomaz, P. ${ }^{* *}$, Rodrigues, P.S. ${ }^{* * *}$, Mirão, $\mathrm{J}^{* * * * *}$, Dias, C. ${ }^{*}$ Caldeira, A.T.*

*HERCULES Laboratory \& Évora Chemistry Centre, University of Évora, Évora, Portugal

***osé Figueiredo Laboratory, General Directorate for Cultural Heritage, Lisbon, Portugal

*** CHAIA \& HERCULES Laboratory, University of Évora, Évora, Portugal

*****HERCULES Laboratory \& Évora Geophysics Centre,University of Évora, Évora, Portugal.

\section{Email: tasf@uevora.pt}

Teotónio of Braganza (1530-1602) was the fifth son of Duke Jaime I of Braganza and his second wife, Joana de Mendonza. The Braganza's were the most important of the Portuguese noble families, which became the $4^{\text {th }}$ and last dynasty of the kingdom. Teotónio rose to archiepiscopal rank in 1544 and became the $4^{\text {th }}$ Archbishop of Évora from 1578 until his death. He also held other several ecclesiastical positions, namely Bishop of Fez and royal adviser of King Philip II. D. Teotónio met and kept up correspondence with people as Teresa de Ávila and Bartolomeu dos Mártires and he had in his service artists like the painter Duarte Frisão and the goldsmith João Duarte. He founded in his archdiocese several monasteries, convents and hospitals, including the Monastery of the Carthusian of Scala Coeli (1587) that received his library, consisting of rare printed and manuscript books. Under his governance, the archbishop's palace and the cathedral suffered renovation and restoration works to where he ordered a new set of ecclesiastical vestments and liturgical objects. The liturgical cope (ME 172/1) under study (Fig. 1), together with a dalmatic, belong nowadays to the Évora Museum and make part of one of those set of ecclesiastical vests. From the same set, a chasuble, with the court of arm of D. Teotónio, is in the Sacred Art Museum and the altar frontal is in Saint Vincent church, belonging to the Town Hall. In order to clarify if these four objects belong to the same set, their material study is a fundamental issue.

Thirty eight samples, between 3 and $5 \mathrm{~mm}$ from different points representing the different metal thread typologies and coloured silk yarns were collected for the material studies. Optical observation of sampled metal threads and silk yarns was carried out in a Leica M205C microscope. A Hitachi S-3700N variable pressure scanning electron microscope coupled with a Brüker energy dispersive X-ray spectrometer were used for surface and cross-section morphological characterisation and chemical analysis of the metal threads. Acceleration voltages of $5.0 \mathrm{kV}$ (for the fibres) and $15.0 \mathrm{kV}$ (for the metal threads) were used for SEM imaging and $20.0 \mathrm{kV}$ was used for EDS analyses. An LCQ Advantage ThermoFinnigan mass spectrometer equipped with an ESI source, using an ion trap mass analyser and a PDA detector was coupled to an HPLC system and was used for dyed fibres analysis.

The Liturgical Cope was made of a variety of materials that included two different typologies of metal threads, dyed silk yarns and vegetable yarns used in the warp/weft. It is in good conservation status, although some damaged areas were found either due to mechanical action or microbiological attack. The two main types of metal threads recorded were silver drawn wire and silver strips or gilded silver strips wound around a yellow silk core. Gilding is more extensive on the external side of the threads. The Ag-based alloy wire composition is ca. $97 \%$ silver, $1.5 \%$ gold and $1.5 \%$ copper (\%wt). For the strips, there is no difference in composition between the gilded and the not gilded ones, which are richer in copper (87-91\% silver, 7-10\% copper and $1-4 \%$ gold, \%wt) than the wires. Related with the process of production of the silver alloys, $\mathrm{Cu}$ particles were sometimes found (Fig. 2). As to the fibres, they present a degraded state, exhibiting roughened surfaces with damage of the silk structure and different types of fractures (Fig. 3). Al was the mordant used to the silk fibres, except for the silver threads core silk yarns, which seem to be unmordanted. Luteolin and 
apigenin glycosides, identified in the core silk yarns, indicate the use of a yellow dye source, while red fibres revealed the presence of carminic acid and its isomers, alizarin and Type $\mathrm{C}$ compound. Carminic acid is the major constituent of cochineal and alizarin is one of the major compounds of Madder spp. Type C compound has been identified as a degradation product of brazilwood dye.

Acknowledgements

The authors acknowledge Jorge Oliveira (José Figueiredo Laboratory, DGPC) for the photographs of the Liturgical Cope.

[1] Espanca, T., "Nova miscelânea: D. Teotónio de Bragança - um prelado eborense do tempo de Camões (1530-1602)", in A cidade de Évora. Évora: V.40-41, n.67-68, p.137-147, 1984/85.

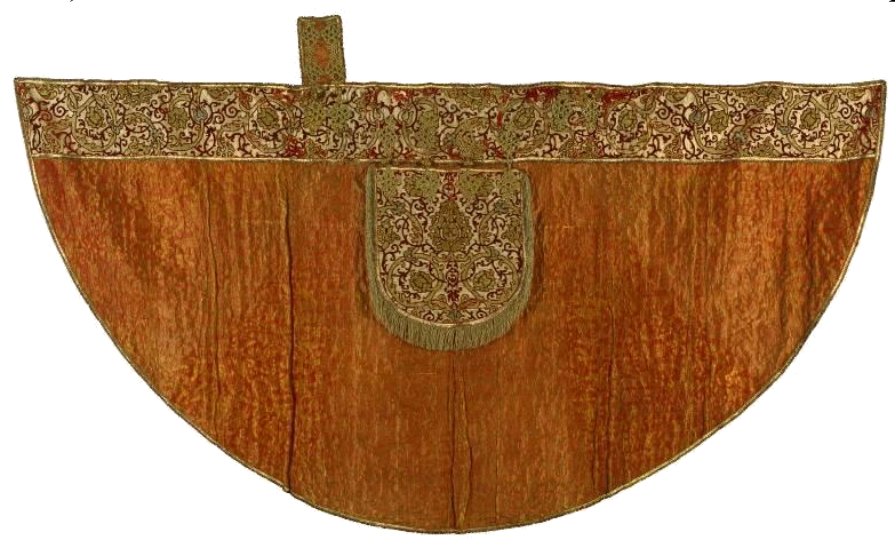

Figure 1. Liturgical cope belonging to D. Teotónio of Braganza.

Dimensions: $(285 \times 140) \mathrm{cm}$.
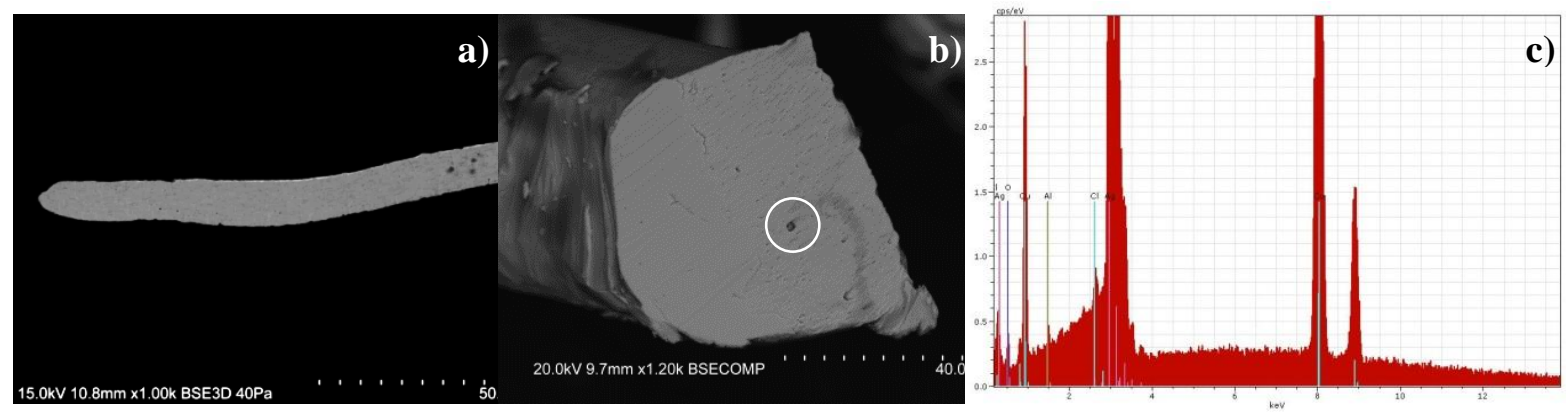

Figure 2. SEM micrographs of a) a thin section of a gilded metal strip, b) a silver wire c) EDS analysis of the point marked in $\mathrm{b}$ ) suggesting the presence of a $\mathrm{Cu}$ particle.

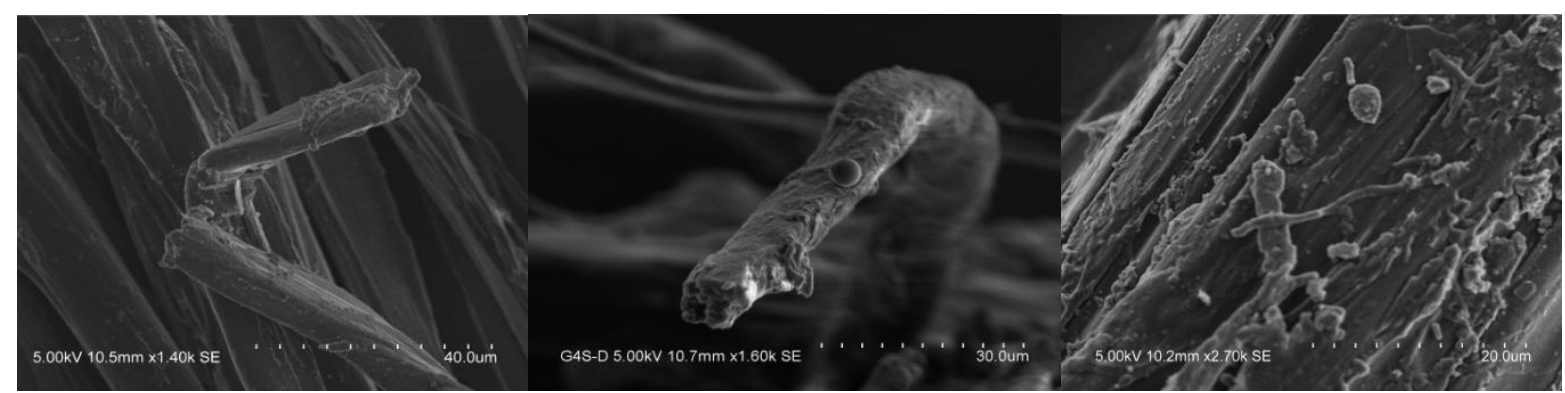

Figure 3. SEM micrographs of the historical fibres exhibiting fracture, roughened surface and biological colonization. 